\title{
Utilisation du lactosérum comme milieu pour transformer le grain égrugé de colza selon un procédé microbiologique
}

\author{
par \\ POZNANSKI S., BEDNARSKI W. et JAKUBOWSKI J. \\ Institut du Génie et de la Biotechnologie alimentaire, \\ Université agricole d'Olsztyn (Pologne)
}

\section{I. - INTRODUCTION}

Au cours des dernières années, on a pris beaucoup d'intérêt à l'utilisation des protéines de plantes oléagineuses, telles que le soya, les semences de coton, d'arachides, de tournesol, etc.

En Pologne, au Canada, en France et en beaucoup d'autres pays, des déchets de l'industrie des corps gras, et notamment le grain égrugé de colza après délipidation, jouent un rôle important dans la production de mélanges fourragers. Un facteur qui limite l'utilisation du grain égrugé de colza pour la production des fourrages est représenté par des substances goitrogènes qu'il contient. Des combinaisons soufrées, considérées comme goitrogènes, se trouvent dans le grain égrugé de colza sous forme de thioglucosides, biologiquement inactifs. Les substances biologiquement actives sont libérées des thioglucosides par hydrolyse enzymatique [10]. Au cours de l'hydrolyse, la plupart des thioglucosides forment des isothiocyanates (ITC), combinaisons qui se caractérisent par leur odeur désagréable, âcre et mordante [9]. Outre les dérivés des ITC, l'hydrolyse des thioglucosides peut contribuer à la formation d'une autre substance biologiquement active qu'on appelle le L-5-vinyl-2-thiooxasolidon [9]. Il est formé par la cyclisation de l'ITC-3-butenyl.

Les propriétés goitrogènes des isothiocyanates (ITC) consistent en une activité concurrente à l'iode. Par contre, le L-5-vinyl-2-thiooxasolidon inhibe l'action de la peroxyde de la thyroïde, ce qui peut finir par l'inactivation des hormones de thyroïde.

La quantité de thioglucosides contenue dans les semences de colza dépend de facteurs différents, tels que la manière de récolter les semences et de les sécher, la variété des semences et l'environnement de la culture [3]. Outre les facteurs naturels énumérés, 
le niveau des combinaisons goitrogènes du grain de colza égrugé peut être influencé par la technique de traitement du grain $[9,10]$.

Dans la littérature mondiale, on a trouvé dernièrement des rapports qui proposent des procédés nouveaux du traitement des grains égrugés de colza après l'extraction, qui consistent en la dégradation des substances goitrogènes du grain égrugé de colza par des microorganismes $[7,11]$.

La détoxication des combinaisons goitrogènes du grain de colza étant un problème important dans l'économie des pays de climat tempéré, nous avons voulu essayer de dégrader les substances dérivées des thioglucosides du grain égrugé de colza par un procédé microbiologique.

Pour transformer le grain égrugé de colza, on a décidé d'utiliser des bactéries et des moisissures, en les cultivant dans un milieu composé de grain égrugé de colza additionné d'une quantité correspondante de lactosérum déprotéiné.

L'addition de lactosérum avait pour but non seulement de supplémenter le milieu en composants énergétiques pour des procédés de fermentation, mais aussi d'utiliser le lactosérum qui constituerait un élément complémentaire d'affouragement, enrichi de la biomasse des micro-organismes utilisés, accumulés par leur culture.

\section{II. - PROTOCOLE EXPERIMENTAL}

Les espèces suivantes de moisissures ont été choisies pour nos expériences : Oospora lactis, Zygorrhynchus meelleri, Rhizopus oligosporus, Endothia parasitica, Penicillium chrysogenum, Byssochlamys fulva. A côté des moisissures, des souches de bactéries Escherichia coli et Lactobacillus helveticus, furent aussi employées dans nos essais.

\subsection{Préparation du milieu}

Le milieu était préparé à partir de lactosérum obtenu au cours de la fabrication de fromages et qui avait subi une déprotéinisation antérieure. Les protéines séparées étaient employées pour les besoins alimentaires. Après la déprotéinisation, le lactosérum était additionné des éléments indispensables : extrait de phosphate d'ammonium d'engrais, en quantité correspondante à $0,7 \mathrm{~g}$ de phosphate pour $100 \mathrm{~g}$ de lactose présent dans le lactosérum, 0,1 p. 100 $\mathrm{Mg} / \mathrm{NO} *$. $6 \mathrm{H}_{2} \mathrm{O}, 0,002$ p. $100 \mathrm{Zn}_{3} / \mathrm{PO}_{4} / 2$. Comme source d'azote, 2,2 g d'urée pour $100 \mathrm{~g}$ de lactose était ajouté au lactosérum. Le milieu ainsi préparé était pasteurisé à $95^{\circ} \mathrm{C}$ pendant $20 \mathrm{mn}$.

Le grain égrugé de colza était introduit dans le milieu à raison de deux parties de lactosérum pour une partie de grain égrugé, en poids. Le mélange avait une consistance pâteuse. 


\subsection{Cultures des bactéries}

Le milieu composé de grain égrugé de colza et de lactosérum était inoculé à l'aide des bactéries en question. Les bactéries étaient cultivées à $37^{\circ} \mathrm{C}$ pour Escherichia coli et à $45^{\circ} \mathrm{C}$ pour Lactobacillus helveticus. Au cours de l'expérimentation, la durée de culture fut changée. Elle durait $2 \mathrm{j}$ ou $10 \mathrm{j}$. Après incubation, le milieu était séché à $60^{\circ} \mathrm{C}$, broyé et conservé dans des bocaux en verre.

\subsection{Culture des moisissures}

Le milieu était ensemencé avec l'inoculum de la moisissure choisie, et placé sur des planches perforées (en couches minces) dans l'armoire à thermostat (étuve) aérée avec un ventilateur. Les moisissures étaient cultivées à $25^{\circ} \mathrm{C} \pm 1^{\circ} \mathrm{C}$ pendant $72 \mathrm{~h}$, puis le tout était séché à la température de $60^{\circ} \mathrm{C}$ et conservé à l'abri de l'humidité.

\subsection{Cultures mixtes de bactéries et de moisissures}

En premier lieu, Lactobacillus helveticus ou Escherichia coli était multiplié en milieu composé de grain égrugé de colza et de lactosérum, selon le procédé décrit au paragraphe 2.2. Ensuite, le milieu avec la biomasse des bactéries multipliées était ensemencé avec l'inoculum de la moisissure désirée et le procédé était continué comme indiqué au paragraphe 2.3 .

Avant et après la culture des micro-organismes, était déterminée la teneur du milieu de grain égrugé de colza et de lactosérum en éléments suivants : extrait sec, azote total (méthode de Kjeldahl), azote précipitable par l'acide trichloracétique (TCA) à 12 p. 100, sucres réducteurs (lactose) par le procédé de Bertrand, groupes libres $\mathrm{SCN}^{-}$ et groupes $\mathrm{SCN}^{-}$totaux [1], ITC-3-butenyl et L-5-vinyl-thiooxasolidon [2].

\section{III. - RESULTATS ET DISCUSSION}

Dans la première étape de l'expérimentation, le milieu a été caractérisé par l'analyse de la composition du grain égrugé de colza, du lactosérum et du milieu total qui était obtenu en mélangeant tous les éléments indispensables pour la culture des micro-organismes (tab. 1). Ce tableau montre que le matériel énergétique (hydrates de carbone), présent dans le milieu, provient principalement du lactosérum. Il faut souligner la proportion élevée des substances azotées précipitables dans le TCA à 12 p. 100. Ces combinaisons consistaient principalement en protéines provenant du grain égrugé de colza.

Dans le milieu de "grain égrugé de colza + lactosérum ", les quantités suivantes de dérivés des thioglucosides ont été constatées : 
TABLEAU 1. - Caractéristiques du milieu

\begin{tabular}{|c|c|c|c|c|c|c|}
\hline $\mathrm{N}^{\circ}$ & Composants du milieu & $\begin{array}{l}\text { Grain égrugé } \\
\text { de colza } \\
\text { (p. 100) }\end{array}$ & $\begin{array}{l}\text { Lactosérum } \\
\text { déprotéinisé } \\
\quad \text { (p. 100) }\end{array}$ & \multicolumn{3}{|c|}{$\begin{array}{c}\text { Milieu } \\
\text { colza }+ \text { lactosérum } \\
\text { (p. 100) }\end{array}$} \\
\hline 1 & Azote total & 6.00 & 0.020 & & 6.10 & \\
\hline 2 & $\begin{array}{l}\text { Protéine totale (pourcentage de } \\
\mathrm{N} \text { total } \times 6.25 \text { ) }\end{array}$ & 37.50 & 0.120 & & 38.12 & \\
\hline 3 & $\begin{array}{l}\text { Azote précipitable en ATC à } \\
12 \text { p. } 100\end{array}$ & 4.60 & 0.014 & & 4.71 & \\
\hline 4 & $\begin{array}{l}\text { Protéine propre (pourcentage de } \\
\mathrm{N} \text { précip. en ACT à } 12 \mathrm{p} .100 \times \\
6.25 \text { ) }\end{array}$ & 28.75 & 0.091 & & 30.75 & \\
\hline 5 & Azote soluble en ACT à 12 p. 100 & 1.39 & 0.006 & & 1.28 & V \\
\hline 6 & Sucres réducteurs (lactose) & - & 4.510 & & 8.36 & \\
\hline 7 & Groupes $\mathrm{SCN}^{-}-$libres & 0.48 & - & & 0.42 & \\
\hline 8 & Groupes $\mathrm{SCN}^{-}-$totaux & 1.41 & - & & 1.32 & \\
\hline 9 & ITC-3-butenyl & 0.38 & - & & 0.29 & \\
\hline 10 & L-5-vinyl-2-thiooxasolidon & 0.53 & - & & 0.48 & \\
\hline
\end{tabular}


ITC-3-butenyl $-0,29$ p. 100 , L-5-vinyl-thiooxasolidon $-0,48$ p. 100 , groupes totaux $\mathrm{SCN}^{-}-1,32$ p. 100 et groupes libres $\mathrm{SCN}^{-}-0,42$ p. 100.

Le tableau 2 représente les pertes de substances goitrogènes dérivées d'ITC-3-butenyl et de 1-5-vinyl-thiooxasolidon. Le degré de dégradation des dérivés d'ITC-3-butenyl s'élevait dans le milieu, après culture des bactéries, jusqu'à $23,9-89,6$ p. 100. Les pertes les plus élevées des combinaisons en question étaient constatées dans le milieu après culture de $10 \mathrm{j}$ de Lactobacillus helveticus. Une réduction moins élevée (30 p. 100) était obtenue après culture de $2 \mathrm{j}$ de la même bactérie. Après culture des bactéries $E$. coli la réduction des combinaisons ITC était deux fois moins élevée que celle qui résultait de la culture de Lactobacillus helveticus. Les résultats obtenus au cours des essais avec les bactéries étudiées indiquent que ce sont l'espèce bactérienne et la durée de la culture qui déterminent le niveau de la réduction d'ITC dans le milieu (tab. 2).

Après culture des moisissures, la réduction des combinaisons toxiques dans le milieu variait de 45,8 à 100 p. 100, exprimée en ITC-3-butenyl. La disparition complète des combinaisons ITC était observée dans la culture de $P$. chrysogenum et $B$. fulva. La réduction un peu moins élevée, de 92,7 à 95,25 p. 100, a été trouvée dans le milieu où les moisissures telles que Endothia parasitica, Zygorrhynchus meelleri et Rhizopus oligosporus avaient été cultivées. Les pertes les moins élevées d'ITC étaient dues à la culture de $P$. roqueforti.

La figure 1 représente les résultats qui indiquent le degré de dégradation des combinaisons dérivées d'ITC-3-butenyl dans le milieu

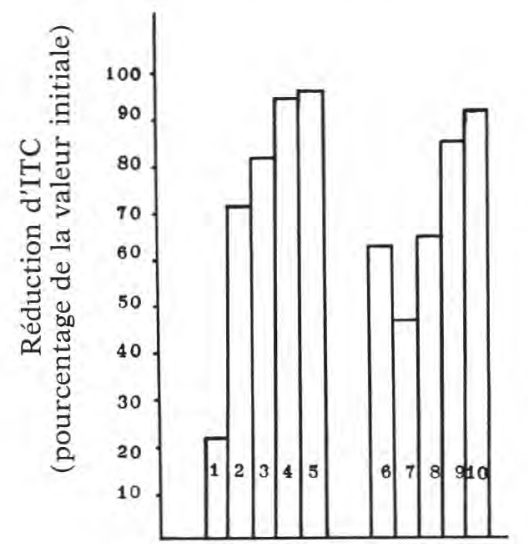

1. E. coli.

2. $P$, camemberti.

3. E. coli + P. camemberti.

4. $R$. oligosporus.

5. E. coli + R. oligosporus.

6. Lactobacillus helveticus.

7. $P$. roqueforti.

8. L. heleveticus $+P$. roqueforti.

9. O. lactis.

10. L. helveticus $+O$. lactis.

fig. 1

Comparaison de l'intensité de la dégradation d'ITC dans le milieu, après culture de bactéries ou de moisissures, et après cultures mixtes de bactéries et de moisissures 
TABLEAU 2

Diminution des substances toxiques d'ITC-3-butenyl et de L-5-vinyl-2-thiooxasolidon dans le milieu après culture des micro-organismes

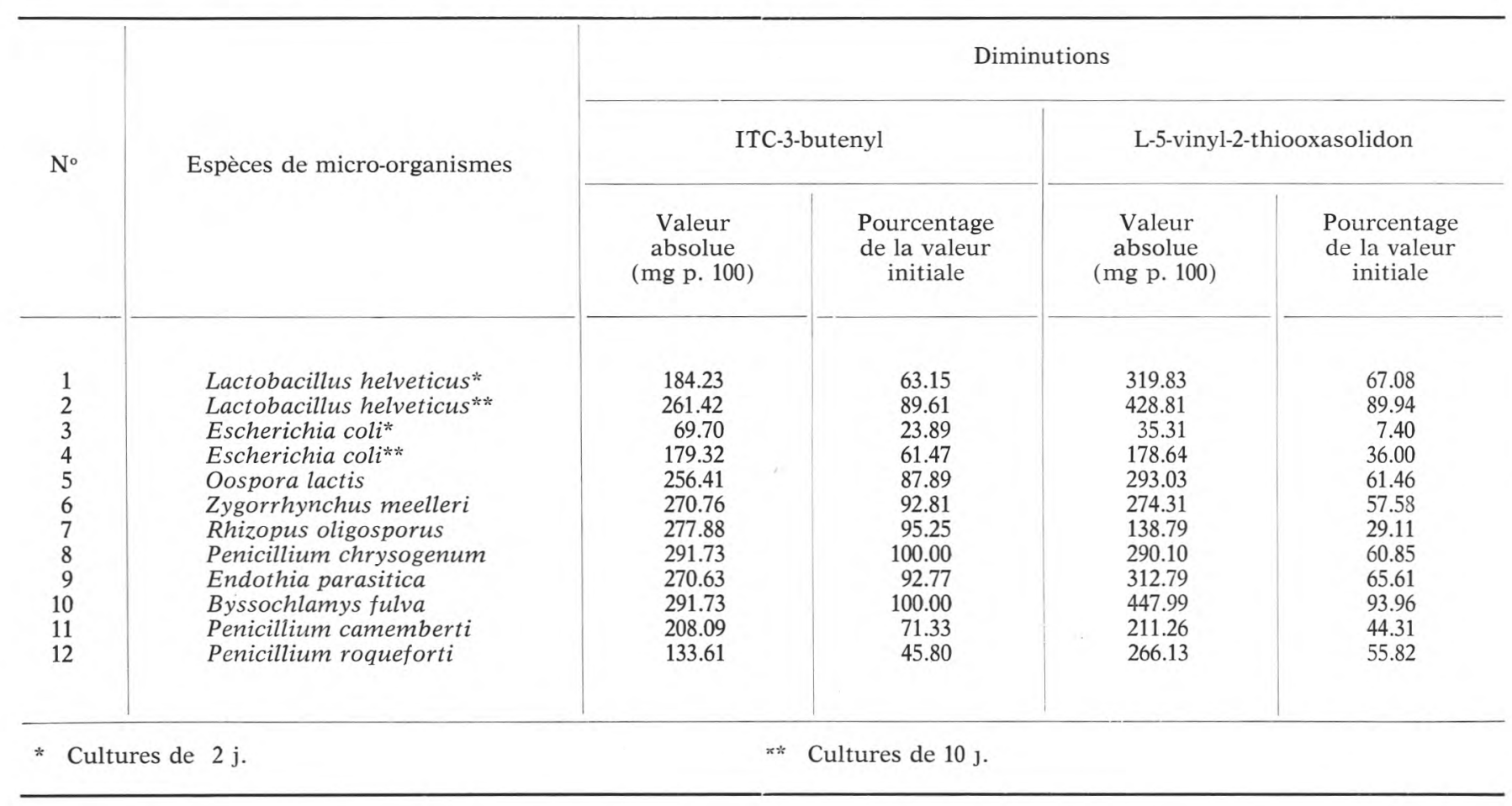


étudié, avec des cultures mixtes (bactéries et moisissures). Des données du diagramme on voit que les bactéries mixtes peuvent contribuer à la dégradation à un degré beaucoup plus élevé des substances dérivées de l'ITC présentes dans le milieu, par comparaison avec les cultures d'une seule espèce, de bactéries ou de moisissures. Dans le milieu où les cultures mixtes de bactéries et de moisissures étaient propagées, la réduction des substances ITC variait de 48,5 p. 100 dans le cas de $B$. helveticus $+P$. roqueforti à 96,6 p. 100 pour E. coli $+R$. oligosporus. Les souches bactériennes qui se développaient dans le milieu contenant le grain égrugé de colza, contribuaient aussi à la réduction des substances dérivées de VTO entre 7,4 et 89,94 p. 100, en fonction de l'espèce des bactéries et la durée de leur incubation (tab. 2). L'intensité de la dégradation de VTO dans le milieu augmentait avec la prolongation de la durée d'incubation des bactéries de 2 à $10 \mathrm{j}$. La culture des moisissures étudiées a provoqué la réduction desdites substances de 29,11 à 94,0 p. 100. La réduction la plus élevée avait lieu dans le cas du milieu où la culture de la moisissure Byssochlamys fulva s'était développée. Par contre, la réduction la moins élevée était observée dans le cas de la moisissure $R$. oligosporus (tab. 2). La figure 2 illustre l'intensité de la dégradation des substances dérivées de VTO dans des milieux où une seule espèce de bactéries ou de moisissures était cultivée, par comparaison avec ceux où des cultures mixtes de bactéries et de moisissures croissaient. On voit donc bien que des cultures mixtes nous permettaient d'atteindre un degré beaucoup plus élevé de dégradation des substances du type VTO que celui qu'on pouvait obtenir au cours des essais parallèles avec des cultures pures de bactéries ou de moisissures. Dans le cas des cultures mixtes de bactéries

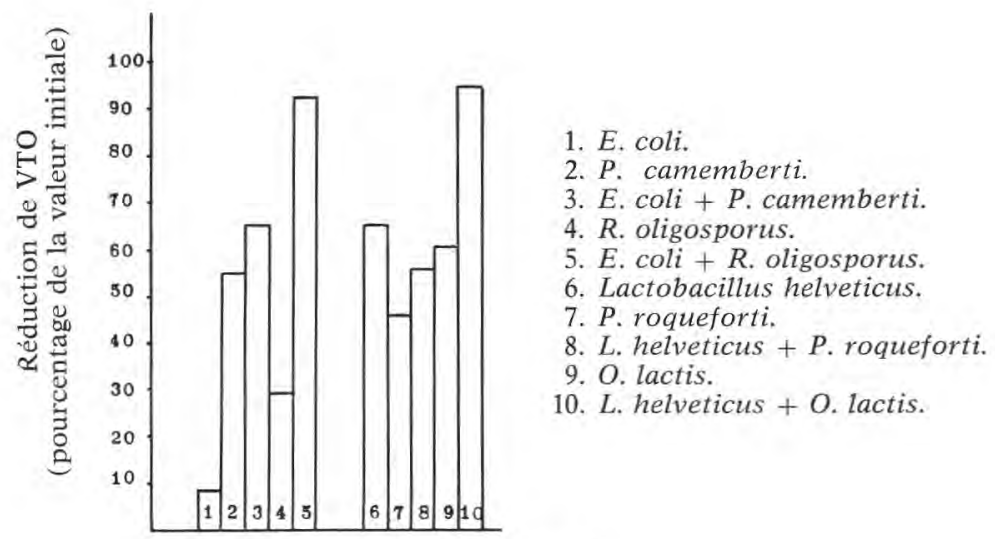

fig. 2

Comparaison de l'intensité de la dégradation de VTO dans le milieu après culture de bactéries ou de moisissures, et après cultures mixtes de bactéries et de moisissures 
et de moisissures, la réduction des dérivés de VTO variait de 41,6 p. 100 dans le cas de la culture de $E$. coli $+R$. oligosporus à 96,9 p. 100 dans le cas de L. helveticus + O. lactis.

Il faut noter que les souches de moisissures qui entraient en comparaison dans les cultures mixtes, étaient justement celles qui avaient montré des aptitudes bien moins fortes à dégrader les dérivés d'ITC ou de VTO (tab. 2) dans les cultures d'une seule espèce.

Le tableau 3 représente les variations de la teneur en groupe $\mathrm{SCN}^{-}$, libres et totaux, des milieux où les micro-organismes étudiés étaient cultivés. Les données de ce tableau indiquent que les milieux de culture de Lactobacillus helveticus et d'Escherichia coli montrent une réduction de la teneur en groupe totaux de $\mathrm{SCN}^{-}$. La réduction la plus élevée de la teneur en groupes totaux de $\mathrm{SCN}^{-}$, atteignant 31,25 p. 100 , était observée dans le cas de la culture des bactéries E. coli. Il est très intéressant de suivre les changements de la teneur en groupes libres de $\mathrm{SCN}^{-}$qui avaient lieu dans le milieu en fonction de la durée de la culture. Dans les 2 premiers jours de la culture, on observait la réduction des groupes libres de $\mathrm{SCN}^{-}$tandis qu'après $10 \mathrm{j}$ d'incubation c'était leur augmentation qui était constatée.

Dans le milieu de culture des moisissures, l'augmentation des groupes totaux de $\mathrm{SCN}^{-}$était observée dans le cas des espèces suivantes : $Z$ meelleri $-90 \mathrm{mg} \mathrm{p.} \mathrm{100,} \mathrm{O.} \mathrm{lactis}-152 \mathrm{mg} \mathrm{p} .100$ et E. parasitica $-153 \mathrm{mg}$ p. 100 .

Pour les autres souches de moisissures, la réduction de la teneur en groupes totaux de $\mathrm{SCN}^{-}$variait de 2,7 p. 100 (36 mg p. 100) dans le cas de $P$. roqueforti à 25,5 p. 100 dans le cas de $P$. chrysogenum.

Les résultats des déterminations des groupes libres de $\mathrm{SCN}^{-}$ dans le milieu après culture des moisissures en montraient l'augmentation très nette par comparaison du nombre de ces groupes dans le même milieu avant culture, à savoir : de 98,7 p. 100 pour $P$. roqueforti à 220,8 p. 100 pour Z. meelleri.

L'analyse de la teneur en groupes totaux de $\mathrm{SCN}^{-}$dans les cultures mixtes des bactéries et des moisissures a montré l'augmentation quantitative de ces groupes pour $L$. helveticus $+P$. roqueforti, $1,52$ p. 100 (20 mg p. 100$)$ et pour E. coli et $R$. oligosporus, 25,5 p. 100 (336 mg p. 100). Dans le cas de la culture E. coli $+P$. camemberti et $L$. helveticus $+O$. lactis, la réduction de la teneur en groupes totaux de $\mathrm{SCN}^{-}$était constatée, variant de 7,44 p. $100(98,00 \mathrm{mg}$ p. 100) à 31,49 p. 100 (425 mg p. 100).

Dans le bilan des groupes libres de $\mathrm{SCN}^{-}$, une augmentation remarquable en était constatée dans les cultures mixtes de bactéries et de moisissures, variant de 49,27 à 169 p. 100 (tab. 3).

Outre l'investigation du degré de la dégradation des substances goitrogènes dans le milieu " grain égrugé de colza + lactosérum ", le bilan des substances azotées et du lactose a été établi au cours de 
TABLEAU 3

Changements de la teneur en groupes $\mathrm{SCN}^{-}$(libres et totaux) dans le milieu avant et après culture des micro-organismes

\begin{tabular}{|c|c|c|c|c|c|}
\hline \multirow{3}{*}{$\mathrm{N}^{\circ}$} & \multirow{3}{*}{ Espèces de micro-organismes } & \multicolumn{4}{|c|}{ Diminution ou augmentation des groupes $\mathrm{SCN}^{-}$} \\
\hline & & \multicolumn{2}{|c|}{ Libres } & \multicolumn{2}{|c|}{ Totaux } \\
\hline & & mg p. 100 & $\begin{array}{l}\text { Pourcentage } \\
\text { de la valeur } \\
\text { initiale }\end{array}$ & mg p. 100 & $\begin{array}{c}\text { Pourcentage } \\
\text { de la valeur } \\
\text { initiale }\end{array}$ \\
\hline $\begin{array}{r}1 \\
2 \\
3 \\
4 \\
5 \\
6 \\
7 \\
8 \\
9 \\
10 \\
11 \\
12 \\
13 \\
14 \\
15 \\
16\end{array}$ & $\begin{array}{l}\text { L. helveticus* } \\
\text { L. helveticus }{ }^{* *} \\
\text { E. coli* } \\
\text { E. coli** } \\
\text { O. lactis } \\
\text { Z. meelleri } \\
\text { R. oligosporus } \\
\text { P. chrysogenum } \\
\text { E. parasitica } \\
\text { B. fulva } \\
P . \text { camemberti } \\
P . \text { roqueforti } \\
\text { E. coli }+P . \text { camemberti } \\
\text { E. coli }+ \text { R. oligosporus } \\
\text { L. helveticus }+ \text { P. roqueforti } \\
\text { L. helveticus }+ \text { O. lactis }\end{array}$ & $\begin{array}{l}-80.9 \\
+170.1 \\
-\quad 59.0 \\
+230.0 \\
+677.7 \\
+920.3 \\
+678.0 \\
+532.7 \\
+831.9 \\
+638.7 \\
+422.1 \\
+411.2 \\
+366.0 \\
+205.3 \\
+704.5 \\
+299.8\end{array}$ & $\begin{array}{r}19.41 \\
40.75 \\
14.19 \\
55.31 \\
162.63 \\
220.85 \\
162.70 \\
127.83 \\
199.64 \\
153.27 \\
101.30 \\
98.70 \\
87.83 \\
49.27 \\
169.06 \\
71.95\end{array}$ & $\begin{array}{l}-206.1 \\
-\quad 88.0 \\
-254.0 \\
-410.0 \\
+\quad 152.0 \\
+\quad 90.0 \\
-\quad 68.0 \\
-336.0 \\
+153.0 \\
-128.0 \\
-\quad 72.0 \\
-\quad 36.0 \\
-415.0 \\
+336.0 \\
+\quad 20.0 \\
-98.0\end{array}$ & $\begin{array}{r}15.63 \\
6.68 \\
19.27 \\
31.15 \\
11.53 \\
6.83 \\
5.16 \\
25.49 \\
11.61 \\
9.71 \\
5.40 \\
2.70 \\
31.49 \\
25.49 \\
1.52 \\
7.44\end{array}$ \\
\hline
\end{tabular}

* Cultures de $2 \mathrm{j}$.

** Cultures de $10 \mathrm{j}$. 
l'expérimentation présente pour déterminer la teneur du milieu en ces composants avant et après culture des micro-organismes. Les résultats obtenus ont été rassemblés dans le tableau 4 . La multiplication de la masse cellulaire des micro-organismes dans le milieu y faisait augmenter le taux de substances azotées précipitables dans le TCA à 12 p. 100 (p. 100 d'azote $\times 6,25)$ de 1,68 p. 100 dans le cas de la culture des bactéries $L$. helveticus à 34,8 p. 100 pour la culture de la moisissure Z. meelleri. L'augmentation des protéines observée s'effectuait en grande partie aux dépens des combinaisons azotées non-protéiques présentes dans le milieu. La diminution des substances azotées précipitables dans le TCA à 12 p. 100 variait de 9,8 à 92,25 p. 100 selon les micro-organismes employés et le procédé de la culture.

Les changements de la teneur en substances azotées qui s'effectuaient dans le milieu après culture des micro-organismes étaient accompagnés de la diminution évidente des substances réductrices du milieu (lactose), variant de 93 p. 100 à 99,4 p. 100.

Nos investigations nous permettent de conclure que la culture des micro-organismes en milieu composé de grain égrugé de colza et de lactosérum peut aboutir à la dégradation presque complète des substances goitrogènes dérivées de l'ITC-3-butenyl. L'intérêt particulier est dû aux résultats qui ont été obtenus par la culture des moisissures, telles que $B$. fulva et $P$. chrysogenum. En cultivant ces espèces en milieu composé de grain égrugé de colza et de lactosérum, la détoxication complète des dérivés d'ITC a été accomplie. Il faut souligner que les micro-organismes étudiés se caractérisaient par l'hydrolyse spécifique des substances nuisibles en question. Dans les cultures des divers organismes, les dérivés d'ITC et ceux de VTO étaient dégradés avec une intensité différente. Ce n'est que dans le cas de la bactérie Lactobacillus helveticus et de la moisissure Byssochlamys fulva qu'une large dégradation d'ITC et de VTC était observée simultanément. La portée de la dégradation des substances nuisibles présentes dans le milieu pouvait être étendue d'une manière évidente par l'application de cultures mixtes des bactéries $E$. coli ou $L$. helveticus avec des moisissures qui, dans des cultures d'une seule espèce, avaient été trouvées moins aptes à la dégradation de VTO, ainsi qu'à celle d'ITC-3-butenyl.

Cultivés en milieu de grain égrugé de colza et de lactosérum, les micro-organismes étudiés possédaient l'aptitude d'hydrolyser des combinaisons contenant des groupes $\mathrm{SCN}^{-}$. Dans la plupart des échantillons, on a observé une augmentation évidente des groupes libres $\mathrm{SCN}^{-}$dans le milieu où les organismes avaient été cultivés, tandis que la teneur en groupes totaux de $\mathrm{SCN}^{-}$diminuait. Ce phénomène se manifestait d'une manière la plus évidente dans le cas des cultures de moisissures, où dans des cultures mixtes de bactéries et de moisissures. 
Caractéristiques de la biosynthèse de la protéine par des bactéries et des moisissures cultivées en milieu composé de grain égrugé de colza et de lactosérum

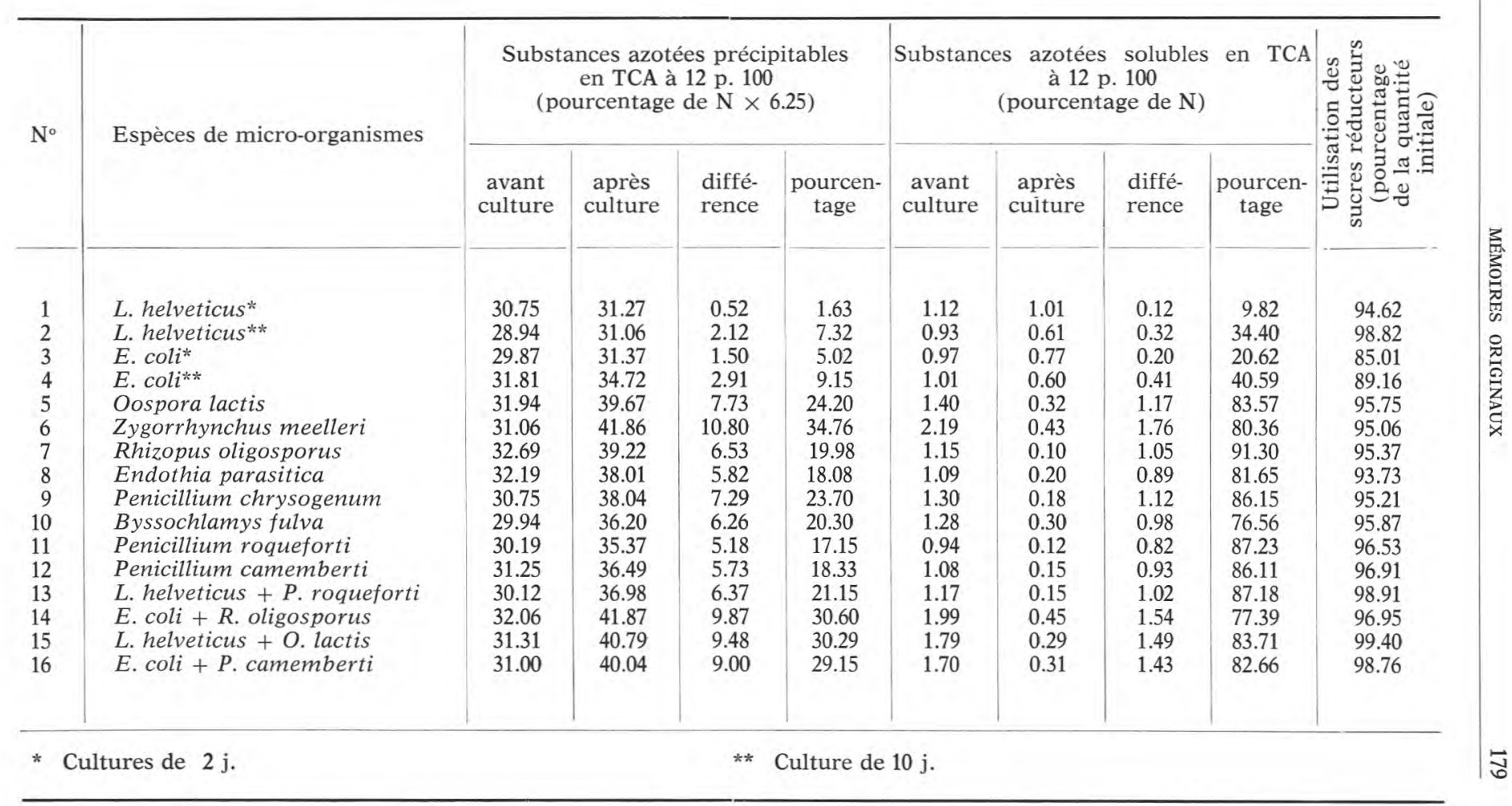


Dans nos expériences avec les moisissures telles que $B$. fulva et $P$. chrysogenum, ainsi que dans celles avec la culture mixte de $L$. helveticus et $O$. lactis, le degré de dégradation des substances goitrogènes obtenu surpassait celui noté dans les recherches précédemment faites dans notre Institut [12]. Pendant ces expériences le grain égrugé de colza était mélangé avec des pommes de terre pour en faire l'ensilage. Le degré de dégradation des substances goitrogènes était alors de 90 p. 100 environ pour des dérivés d'ITC et 65 p. 100 pour VTC.

Le procédé décrit, portant transformation du grain égrugé de colza par voie microbiologique, permet, outre la dégradation des substances toxiques, d'augmenter la teneur du milieu en protéines. Les résultats obtenus y ont fait monter le taux des protéines de 31,00 p. 100 avant culture à 41,9 p. 100 après la culture des microorganismes. Il faut souligner que la protéine de la biomasse des bactéries et des moisissures étudiées se caractérisait par une quantité élevée de lysine, de $7,1 \mathrm{~g}(16 \mathrm{~g} \mathrm{~N})$ à $9,2 \mathrm{~g}(16 \mathrm{~g} \mathrm{~N})$ [5], acide aminé qui limite la valeur biologique de la protéine de grain égrugé de colza $[6,8]$.

L'enrichissement du milieu de grain égrugé de colza en biomasse de bactéries et de moisissures qui contiennent des protéines de haute valeur et des vitamines du groupe B constitue un argument complémentaire en faveur du procédé proposé pour la détoxication des substances goitrogènes du grain égrugé de colza. Ce procédé l'emporte de façon décisive sur les autres méthodes de détoxication des thioglucosides, par traitement thermique ou rinçage du grain égrugé de colza, dans lesquelles la détoxication complète des substances goitrogènes est suivie par la diminution de la valeur biologique des protéines du grain égrugé de colza (traitement thermique) et même par certaines pertes quantitatives des substances azotées, solubles dans la solution utilisée pour rincer le grain égrugé $[8,9,10]$.

La vulgarisation de la méthode microbiologique pour la détoxication des substances goitrogènes dans le grain égrugé de colza, que nous avons décrite ici, peut contribuer à l'utilisation plus efficace aussi bien du grain égrugé de colza que du lactosérum pour la production de mélanges fourragers.

\section{R és u m é}

Nous avons étudié des possibilités de détoxication des dérivés de thioglucosides présents dans le grain égrugé de colza en cultivant des bactéries et des moisissures en milieu composé de grain égrugé de colza et de lactosérum. Avant et après la culture des microorganismes, la teneur du milieu en ITC-3-butenyl, en L-5-vinyl-2-thiooxasolidon (VTO) et en groupes $\mathrm{SCN}^{-}$a été déterminée. 
On a constaté que le degré de dégradation des dérivés d'ITC était de $61,4-89,6$ p. 100 dans le milieu de culture des bactéries, et de 45,8-100,0 p. 100 dans celui des moisissures. Les dérivés de VTO diminuaient de 7,4-89,9 p. 100 dans le milieu des bactéries et de 44,3-93,9 p. 100 dans le milieu de culture des moisissures. La détoxication des dérivés d'ITC et de VTO a pu être intensifiée au moyen de cultures mixtes de bactéries et de moisissures. Après culture des micro-organismes, les changements essentiels de la teneur en groupes $\mathrm{SCN}^{-}$(totaux et libres) a été démontrée.

Le milieu de grain égrugé de colza et de lactosérum était supplémentairement enrichi en protéines par la biomasse des microorganismes qui s'y étaient multipliés. L'augmentation des protéines dans le milieu allait jusqu'à 2-32 p. 100, selon le micro-organisme utilisé.

\section{Utilisation of whey as a medium for purifying rape ground grain by microbiological procedure}

\section{S u m m a r y}

Studies were made on possibilities to detoxify thioglucoside derivates, as present in rape ground grain, by growing moulds and bacteria on a medium composed of rape ground grain and whey. The contents of ITC-3-butenyl, L-5-vinyl-2-thiooxasolidon (VTO) and $\mathrm{SCN}^{-}$groups were determined in the medium before and after the cultivation of microorganisms.

The degradation extent of ITC derivates, as due to the growth of bacteria and moulds, was found to be 61.4-89.6 p. 100 and 45.8-100 p. 100, respectively, while the respective decreases of VTC derivates in the medium were $7.4-89.8$ p. 100 and $44.3-93.9$ p. 100 . The detoxification of ITC and VTO derivates could be intensified by using mixed cultures of bacteria and moulds. Significant changes on both total and free $\mathrm{SCN}^{-}$group contents were observed in the media, in which microorganisms had been cultivated.

The rape ground grain and whey medium was supplementarily enriched with proteins by the biomass of the microorganisms studied which had been grown on that medium. The increase of protein in the medium amounted to $2-32$ p. 100 , depending on microorganisms species used.

\section{Verwendung von Molke als Nährboden zur an Hand von mikrobiologisches Verfahren durchgeführten Rappsschrottveradelung}

\section{Zusammenfassung}

Die Möglichkeit, die im Rapsschrott befindlichen ThioglucosidDerivate durch die auf dem Rapsschrott und Molke enthaltenden 
Nährboden gezüchteten Bakterien und Schimmelpilze abzubauen, ist untersucht worden. Der Gehalt von ITC-3-Butenyl, L-5-Vinly-2-Thiooxasolidon (VTO) und $\mathrm{SCN}^{-}$-Gruppen wurde im Nährboden vor und nach der Züchtung der Mikroorganismen bestimmt.

Es wurde festgestellt, dass der durch die Bakterienzüchtung verursachte Abbaugrad der ITC-Derivaten im Nährboden 61.4-89.6 p. 100 beträgt. Für die Schimmelpilze die entsprechenden Zahlen waren 45.8-100.0 p. 100. Die Abnahmen der VTO-Derivate im Rapsschrott betrugen 7.4-89.8 p. 100 bei der Bakterienzüchtung und 44.3-93.9 p. 100 bei der Schimmelpilzzüchtung. Die Entgiftung von ITC- und VTO-Derivaten konnte durch die Anwendung der Mischkulturen der Bakterien und Schimmelpilze intensiviert werden. Auch wesentliche Anderungen im Gehalt von gesammten und freien $\mathrm{SCN}^{-}$wurden im Nährboden nach der Züchtung der Mikroorganismen aufgewiesen.

Der aus Rapsschrott und Molke bestehende Nährboden wurde durch die Biomasse der darauf vermehrten Mikroorganismen zusätzlich mit Eiweiss angereichert. Die Eiweisszunahme im Nährboden betrug von 2 bis 32 p. 100, je nach der Art der Mikroorganismen.

\section{Références bibliographiques}

[1] Aldrige (W. N.) (1945) - Analyst., 70, p. 474.

[2] Appelouist (L. A.) (1967). - J. Sci. Food Agric., 18, p. 510.

[3] Baczynska (B.), Krzymanski (J.), Wiazecka (K.) (1970). - Hod. Rosl. Aklim., 14,6, p. 472.

[4] Bednarski (W.), Jakubowski (J.), Poznanski (S.), Surazynski (A.). (1970) Le Lait, 50, 485, p. 285.

[5] Bednarski (W.), Poznanski (S.), Surazynski (A.), Jakubowski (J.) (1971). Przem, Spoz., 25, p. 102.

[6] BeZa (R.) (1967). - Aminokwasy w zywieniu zwierzat. PWRiL W-wa.

[7] Chanet (M.) (1970). - Revue Française des Corps Gras, 5, p. 309.

[8] Pogorzelska (E.) (1970). - Proby wykorzynstania bialek rzepaku jako dodatku do zywnosci. Dysertation-Olsztyn.

[9] Rutkowski (A.), Kozlowska (H.), Chudy (J.) (1965). - Zeszyty Problemowe Nauk Roln., 219-220, p. 81.

[10] Rutkowski (A.), Kozlowska (H.), Pokorny (J.) (1966). - Roczn. Techn. $i$ Chemii Zywnosci PAN XII, p. 278.

[11] Staron (T.) (1970). - Ind. Alim. Agric., 6, p. 743.

[12] WEIDNER (S.) (1971). - Zmiany pochodnych tioglukozydow zawartych $w$ srucie rzepakowej w procesie kiszenia. Dysertation-Olsztyn. 